\title{
AVALIAÇÃO DO DESEMPENHO DO ÍNDICE $\triangle$ NBR PARA A IDENTIFICAÇÃO DE ÁREAS INCENDIADAS NA MICRORREGIÃO DE UBERABA, MG
}

\author{
CLAUDIO MANOEL PANTALEÃO JÚNIOR \\ Graduado em Geografia, Universidade Federal do Triângulo Mineiro ${ }^{1}$ \\ cmpantajr@hotmail.com
}

\author{
RICARDO VICENTE FERREIRA \\ Doutor em Geografia, Professor da Universidade Federal do Triângulo Mineiro ${ }^{1}$ \\ ricardo.ferreira@uftm.edu.br
}

\begin{abstract}
RESUMO: O sensoriamento remoto é fundamental para avaliar as alterações provocadas por incêndios florestais sobre o uso do solo, pois fornece cobertura temporal e espacial ao monitoramento e análise destes eventos. A proposta deste trabalho é mapear as alterações por incêndios na Microrregião de Uberaba e analisar os usos dos solo afetados pelos episódios ocorridos entre os dias 03 de agosto e 12 de setembro de 2017. Foram utilizadas imagens do satélite Sentinel-2A, sensor MSI, aplicou-se uma metodologia de análise temporal de evento pré-fogo e pós-fogo e mediu-se a exatidão dos resultados pelo coeficiente Kappa. Foram estimados 11.129ha de área queimada, sendo 10.437ha ocorridos sobre cultivos agrícolas, contudo, o coeficiente kappa de 55,2\% denota concordância moderada. A precisão pode ser aumentada se o método for aplicado somente em áreas com incêndios conhecidos, excluindose áreas estimadas. Os incêndios foram mais intensos nas área de cultivo da cana de açúcar.
\end{abstract}

PALAVRAS-CHAVE: Vegetação; Sentinel-2A; queimadas; kappa.

\section{PERFORMANCE EVALUATION OF $\triangle$ NBR INDEX FOR IDENTIFICATION OF FIRE AREAS IN THE MICRO-REGION OF UBERABA, MG}

\begin{abstract}
Remote sensing is essential to assess changes caused by forest fires on land use, as it provides the temporal and spatial coverage for monitoring and analyzing these events. The purpose of this work is to map alterations caused by fires in Uberaba Microregion and to analyze land uses affected by wildfires between August 3 and September 12, 2017. We used Images from the Sentinel-2A satellite, MSI sensor and applied a pre-fire and post-fire temporal analysis methodology and to validate the accuracy of the results a Kappa coefficient was used. There were an estimated a burned area of 11,129ha, where 10,437ha occurred on agricultural crops, however, the kappa coefficient of $55.2 \%$ denotes moderate agreement. Accuracy can be increased if the method is applied only in areas with known fires, excluding estimated areas. The fires were more intense on sugar cane cultivation.
\end{abstract}

KEYWORDS: Vegetation; Sentinel-2A; burned; kappa.

\section{EVALUACIÓN DEL DESEMPEÑO DEL ÍNDICE $\triangle$ NBR PARA LA IDENTIFICACIÓN DE ÁREAS DE INCENDIO EN LA MICRO REGIÓN DE UBERABA, MG}

RESUMEN: La teledetección es esencial para evaluar los cambios causados por los incendios forestales en el uso de la tierra, ya que proporciona cobertura temporal y espacial para monitorear y analizar estos eventos. El propósito de este trabajo es mapear las alteraciones causadas por incendios en la Microrregión de Uberaba y analizar los usos del suelo afectados por los episodios ocurridos entre el 3 de agosto y el 12 de septiembre de 2017. Se utilizaron imágenes del satélite Sentinel-2A, sensor MSI. Se utilizó una metodología de análisis temporal pre-incendio y post-incendio y la precisión de los resultados se midió mediante el coeficiente Kappa. Se estima que hubo 11,129ha de área quemada, 10,437ha de las cuales ocurrieron en cultivos agrícolas, sin embargo, el coeficiente kappa de $55.2 \%$ denota un acuerdo moderado. La precisión se puede aumentar si el método se aplica solo a áreas con incendios conocidos, excluidas las áreas estimadas. Los incendios fueron más intensos en la zona de cultivo de la caña de azúcar.

PALABRAS CLAVE: Vegetación; Sentinel-2A; quemadas; kappa.

${ }^{1}$ Endereço para correspondência: Avenida Getúlio Guarita, 159, Departamento de Geografia, Nossa Senhora da Abadia - CEP: 38025-440 - Uberaba, MG. 


\section{INTRODUÇÃO}

O Cerrado é o segundo bioma brasileiro com maior ocorrência de incêndios florestais (INPE, 2020). As modificações ocasionadas pela expansão agrícola levaram ao aumento do número de ocorrência de incêndios, estando estes associados à supressão da cobertura vegetal natural e manejo inadequado do solo (RESENDE, 2017). No Cerrado Brasileiro tem ocorrido uma crescente conversão da vegetação original em áreas agrícolas e, nesse processo, o fogo é utilizado pelo homem inapropriadamente, seja para a renovação de pastagens, limpeza de terreno e inclusive por motivações criminosas (MEDEIROS; FIELER, 2004; SANTOS et al, 2006).

A estiagem prolongada no Cerrado também é um fator que favorece a ocorrência de incêndios neste domínio. A baixa umidade relativa por longo período é uma característica que está relacionada ao domínio morfoclimático: "A natureza física e ecológica dos cerrados possui poucas deficiências hídricas no subsolo superficial, apresentando entrementes fortes deficiências hídricas no ar durante a prolongada estiagem no meio do ano" (AB'SÁBER, 2003, p.120). Em escala regional e local, os incêndios podem gerar grandes perdas ao meio ambiente, afetando diretamente as espécies endêmicas, o solo, além de implicações socioeconômicas importantes, trazendo danos à vida e estruturas (CHUVIECO et al. 2014)

A avaliação da severidade de uma área queimada é um procedimento chave para compreender as alterações dos ambientes naturais frente a ocorrência de incêndios, assim, o mapeamento e quantificação dessa informação torna-se um instrumento de análise da distribuição espacial e dos danos causados pelo fogo à vegetação e fauna, além de aplicar-se à estimativa das emissões de carbono na atmosfera, à análise do potencial à erosão dos solos e à interferência na qualidade da água (BOUCHER et al. 2016).

Os incêndios variam em intensidade e em dimensão espacial e os sintomas dessas alterações sobre a vegetação podem variar desde queimas parciais, com pouca interferência, até à carbonização total do material vivo ou morto disponível para a queima (KOLDEN; SMITH; ABATZOGLOU, 2015; BOUCHER et al. 2016).

O sensoriamento remoto é fundamental no estudo dos impactos advindos dos incêndios florestais, pois fornece cobertura temporal e espacial necessária ao monitoramento e análise dos eventos, suas aplicações voltadas ao estudo dos incêndios requerem o processamento de imagens de satélites de modo a transformá-los em informação pertinente para a análise, por exemplo, através da construção de Índices de Vegetação ou Índice de Queimada por Razão Normalizada. (CARDOZO et al. 2011).

A proposta deste trabalho é mapear as áreas afetadas por incêndios no ano de 2017 na Microrregião de Uberaba e analisar quais coberturas e usos do solo foram mais afetados nos episódios ocorridos nos meses de agosto e setembro de 2017.

\section{ÁREA ESTUDADA}

A Microrregião de Uberaba é uma divisão territorial estabelecida pelo Instituto Brasileiro de Geografia e Estatística (IBGE, 1990) vigente de 1989 à 2017, localiza-se no Estado de Minas Gerais e integra os municípios de Uberaba, Conceição das Alagoas, Delta Campo Florido e Conquista (Figura 1). Segundo o IBGE (2004), a microrregião insere-se no bioma do Cerrado e se caracteriza pela formação savânica, com presença de formação arbórea de baixo porte e densidades de tipo ralo, típico ou denso, encontrando-se ainda formações arbustivas e gramíneas (PEREIRA, 2017).

Durante os meses de maio a setembro ocorre do período seco. A série temporal de 30 anos mostra um balanço hídrico com seis meses de déficit para a estação do INMET da cidade de Uberaba (MG), sendo a maior deficiência hídrica nos meses de agosto e setembro (NOVAIS; BRITO; SANCHES, 2018). Seguindo a escala climática de Köppen, a região insere-se no domínio do clima "Aw" (Tropical com inverno seco) (DUBREUIL et al. 2018). Em decorrência desta característica climática, ocorre o ressecamento da vegetação, propiciando um ambiente 
favorável à ocorrência de incêndios florestais. Existe uma forte relação entre a ocorrência de incêndios e as variações anuais das condições meteorológicas (SANTOS et al. 2016). Na Microrregião de Uberaba os incêndios florestais tem se caracterizado como uma modalidade de desastre e tem se agravado nos últimos anos, mantendo relação com as mudanças no uso da terra e cobertura vegetal, como é possível observar através dos dados disponibilizados pelo sistema de prevenção de incêndios florestais e monitoramento da cobertura vegetal no Cerrado brasileiro, desenvolvido pelo Centro de Sensoriamento Remoto - CSR - UFMG (https://csr.ufmg.br/fipcerrado/).

Figura 1 - Mapa de localização da área de estudo

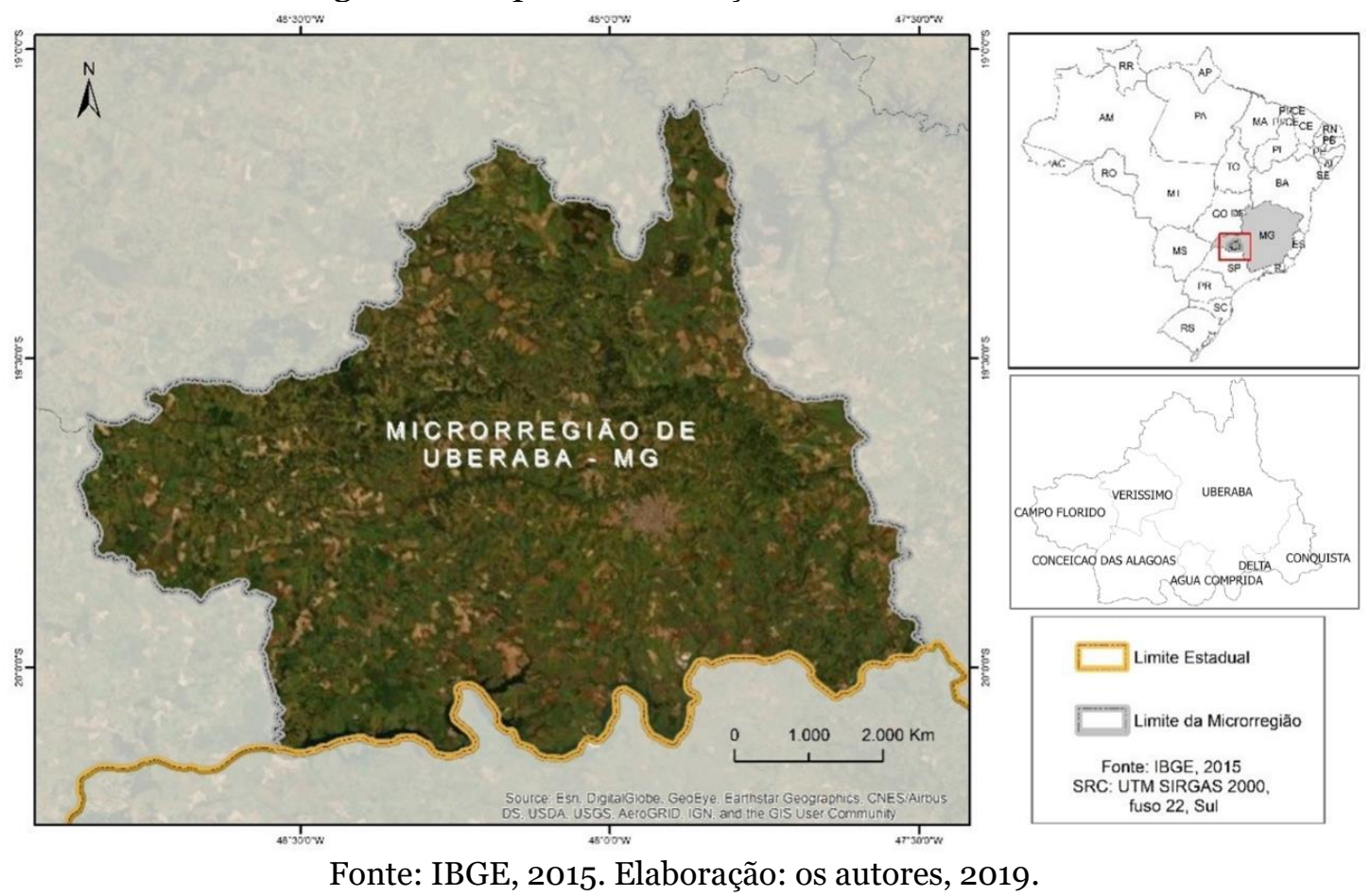

Com o avanço da monocultura e sua expansão territorial no Brasil, a região do Triângulo Mineiro foi incluída a esse processo, já que Minas Gerais apresenta condições naturais que favorecem o cultivo da cana-de-açúcar, especialmente no Triângulo Mineiro/Alto Paranaíba (GOMES DE SOUZA; CLEPS JUNIOR, 2009). O avanço da cultura da cana de açúcar no Triângulo Mineiro, elevou essa região como a maior produtora desta cultura no Estado de Minas Gerais, sobretudo, a partir do ano de 2005 (BRITO; REIS, 2012).

A Microrregião de Uberaba insere-se nesse contexto e passou por significativas mudanças nas últimas décadas, com quantidades expressivas de terras utilizadas para o cultivo da cana de açúcar e com o crescimento de usinas do setor sucroalcooleiro (GOMES DE SOUZA; CLEPS JUNIOR, 2009).

\section{MATERIAIS E MÉTODOS}

Para a realização deste trabalho os materiais utilizados foram: imagens de satélite do sensor Multi-spectral Instrument, pertencente à sonda orbital SENTINEL-2A (S2-MSI) com passagem nos dias 03/08/2017 e 12/09/2017; dados da Cobertura e Uso do Solo de 2017 disponibilizados pelo projeto MapBiomas (PROJETO MAPBIOMAS, 2019); polígonos do limites municipais do Estado de Minas Gerais disponibilizados pelo Instituto Brasileiro de Geografia e Estatística (IBGE, 2019); e Sistema de Informação Geográfica QGIS versão 3.8. A sequência metodológica empregada no processo de aquisição, organização, processamento e análise espacial dos dados está descrita na figura 2. 
Figura 2 - Fluxograma dos procedimentos realizados

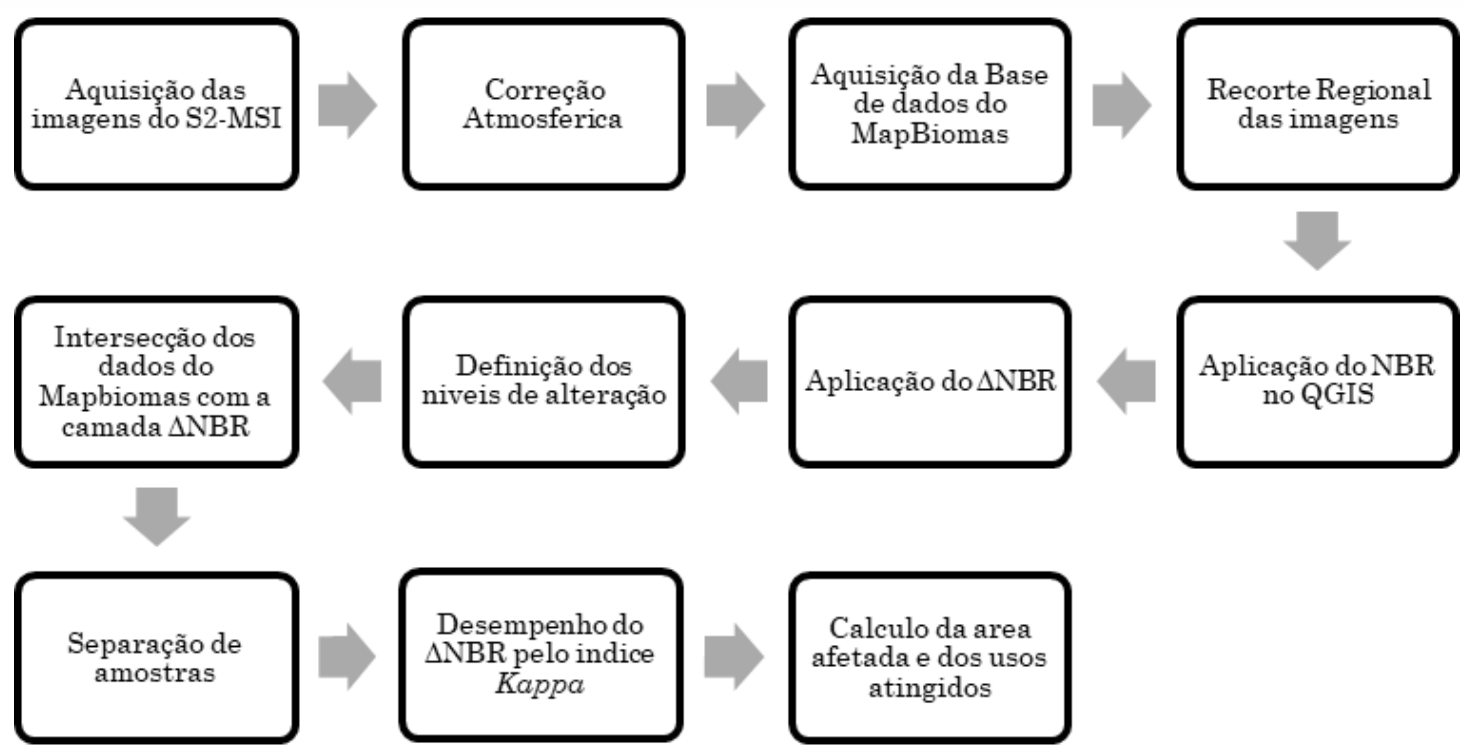

Elaboração: os autores, 2019.

A distribuição espacial dos incêndios e sua intensidade não ocorre de forma homogênea e a análise da intensidade da queima pode oferecer uma perspectiva a respeito dos efeitos do fogo na paisagem (KEY; BENSON, 2006). Experimentos realizados nos ecossistemas florestais do Ocidente dos Estados Unidos mostraram que a análise temporal por meio do comportamento da refletância das bandas NIR (Infravermelho próximo) e SWIR (Infravermelho médio), permite evidenciar as áreas queimadas em relação às superfícies vegetais não queimadas (KEY; BENSON, 2006). A banda NIR (B8 S2-MSI) possui baixa reflectância para a matéria orgânica queimada, como galhos e folhas (matéria morta), mas tem alta refletância para a vegetação verde (viva), por outro lado, a banda SWIR (B12 S2-MSI) reflete a matéria orgânica independente de sua condição, isso permite utilizar as diferentes respostas espectrais de cada banda para normalizar os valores e realçar as áreas queimadas (SILVA; PESTANA; MARTINS, 2019). O Índice de Queimada por Razão Normalizada (NBR) foi proposto por Koutsias; Karteris (1998) e é dado pela seguinte equação:

$$
\mathrm{NBR}=(\mathrm{NIR}-\mathrm{SWIR}) /(\mathrm{NIR}+\mathrm{SWIR})
$$

Onde:

NBR = Índice de Queima por razão Normalizada

NIR = Banda do Infravermelho próximo (no sensor S2 MSI corresponde à banda B8)

SWIR = Banda do infravermelho de ondas curtas (no sensor S2 MSI corresponde à B12).

Considerando que em uma condição de pré-fogo para pós-fogo a faixa NIR diminui e a faixa SWIR aumenta, a combinação de um NBR pré-fogo com um NBR pós-fogo permitirá a aquisição de informações sobre a variação da severidade da área queimada (KEY; BENSON, 2006). Diante disso, para isolar áreas queimadas das áreas não queimadas e, assim, obter um gradiente de variação da alteração provocada pelo fogo, o NBR do pré-fogo é subtraído do NBR pós-fogo aplicando-se a seguinte equação:

$$
\Delta \mathrm{NBR}=\left[N B R_{\text {pre }- \text { fogo }}-N B R_{\text {pos }- \text { fogo }}\right] \quad \text { Eq. } 2
$$

Onde:

$\triangle \mathrm{NBR}=\mathrm{o}$ delta NBR é o índice onde se admite que os valores podem ser correlacionados à magnitude da mudança ambiental causada pelo fogo (KEY; BENSON, 2006).

Cláudio M. Pantaleão Júnior, Ricardo V. Ferreira. Avaliação do desempenho do índice $\Delta$ NBR para a identificação de áreas incendiadas (...) Brazilian Geographical Journal: Geosciences and Humanities research medium, 
A partir do $\triangle$ NBR procedeu-se com a classificação dos níveis de alteração provocados na vegetação. Os valores foram multiplicados pela constante $10^{3}$ para relacioná-los aos termos usados por Key; Benson (1999), contudo os autores destacam que os intervalos de valores $\triangle$ NBR são flexíveis, pois sofrem interferência de fatores como: os limites das faixas espectrais; dos instrumentos imageadores (que variam para cada satélite), além de interferências atmosféricas ou de outra natureza.

A fim de quantificar a área dos ambientes afetados pelos incêndios e validar os resultados, a camada raster com os valores do $\triangle$ NBR foi reclassificada em 10 níveis de alteração, os quais indicam a severidade da queimada. Por interpretação visual, comparou-se os níveis do $\triangle \mathrm{NBR}$ com uma composição colorida RGB da imagem pós-fogo de modo a identificar as áreas conhecidas onde ocorreram incêndios (figura 3).

Figura 3 - Composição colorida R(B3)G(B8)B(B2)


Na figura 3A observa-se a imagem de 03/08/2017. Em 3B a imagem de 12/09/2017, mostra a área afetada por incêndios e fumaça decorrente do fogo ativo.

Fonte: Agência Espacial Européia (ESA), 2017. Elaboração: os autores, 2019.

Para validar os resultados da classificação, e assim obter a precisão dos níveis de alteração e as áreas afetadas pelas queimadas, aplicou-se o coeficiente de concordância de Kappa proposto por Cohen (1960) e atribuído ao sensoriamento remoto por Congalton (1991). O procedimento consistiu em transformar a imagem classificada (níveis $\Delta \mathrm{NBR}$ ) em um modelo vetorial, o que resultou em uma camada com cerca de 5.000 polígonos. A validação foi aplicada sobre uma amostragem randômica de 1.000 feições poligonais, selecionadas com uso da ferramenta "extrair aleatoriamente" disponibilizada no QGIS. Os polígonos foram classificados atribuindo-se o valor o (zero) às áreas não queimadas e 1 (um) às áreas queimadas.

Em um segundo momento, foi realizada a intersecção dos dados $\triangle$ NBR com a camada raster da cobertura e uso do solo (PROJETO MAPBIOMAS, 2019) para a quantificação dos tipos mais afetados pelos incêndios na Microrregião de Uberaba no ano de 2017.

\section{RESULTADOS}

Os valores obtidos pelo $\triangle$ NBR variaram de -1197 até 1564 e foram agrupados em 10 (dez) níveis de alteração. Os 4 níveis de alteração mais baixos mostraram pouquíssima ou nenhuma relação com áreas queimadas. A variação provocada pelos incêndios foi melhor detectada nos níveis de 5 a 10 (tabela 1 ). 
Tabela 1 - Níveis de alteração do $\Delta$ NBR, adaptado de Key e Benson (2006).

\begin{tabular}{|c|c|c|}
\hline Valores & Níveis & Descrição \\
\hline-1197.000 até -500.001 & 1 & \multirow{4}{*}{ Pouca ou nenhuma alteraçãc } \\
\hline-500.000 até -250.001 & 2 & \\
\hline-250.000 até -0.001 & 3 & \\
\hline 0.000 até 249.999 & 4 & \\
\hline 250.000 até 499.999 & 5 & Alteração branda \\
\hline 500.000 até 749.999 & 6 & Alteração moderada \\
\hline 750.000 até 999.999 & 7 & Alteração significativa \\
\hline 1000.000 até 1249.999 & 8 & Queimada recente \\
\hline 1250.000 até 1499.999 & 9 & Queimada ativa I \\
\hline 1500.000 até 1564.999 & 10 & Queimada ativa II \\
\hline
\end{tabular}

Elaborado pelos autores e adaptado de Key e Benson (2006).

Por interpretação visual dos NBR pré-fogo e o NBR pós-fogo foi possível observar alterações causadas pelas queimadas e também alterações que correspondem a vegetação seca. As maiores alterações foram observadas na porção sul da Microrregião, com destaque para os municípios de Uberaba, Água Comprida e Conceição das Alagoas (Figura 4).

Figura 4 - $\Delta$ NBR e Níveis de alterações

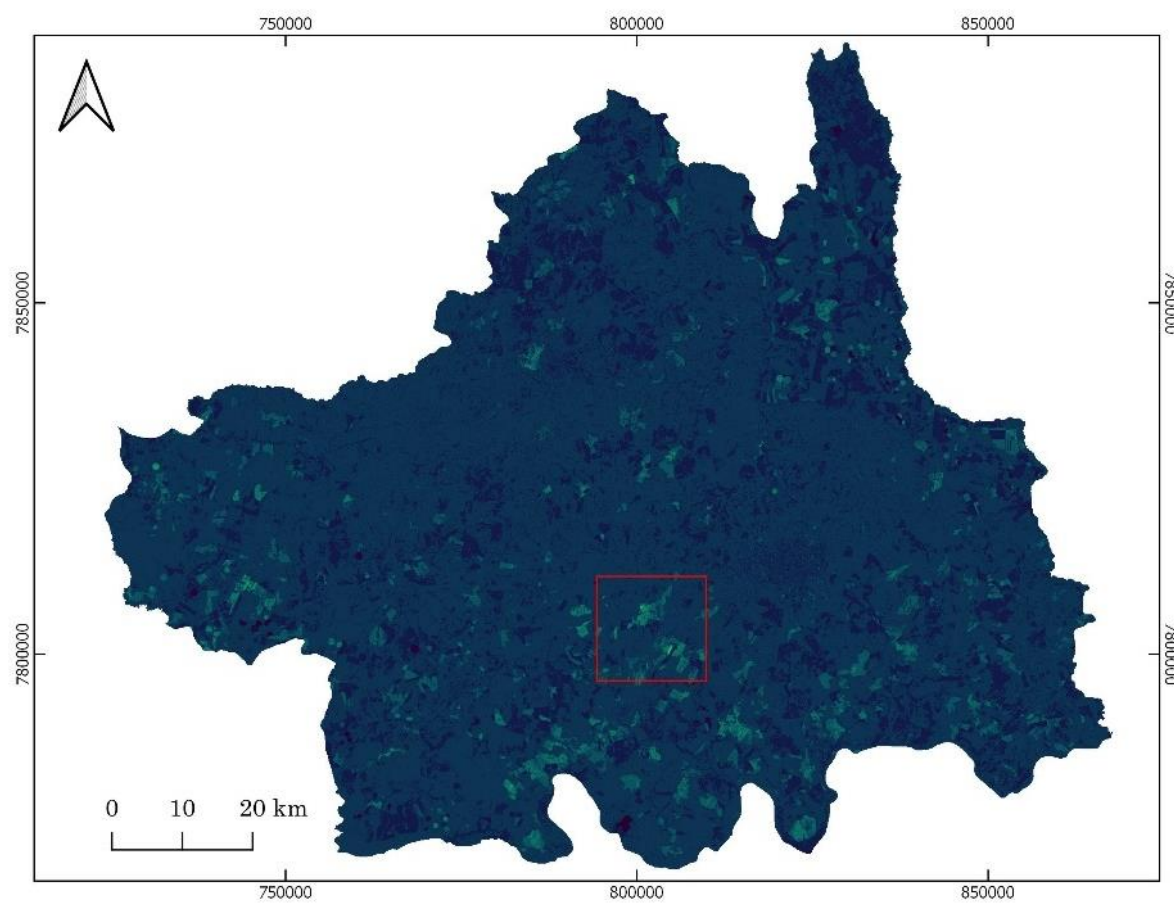

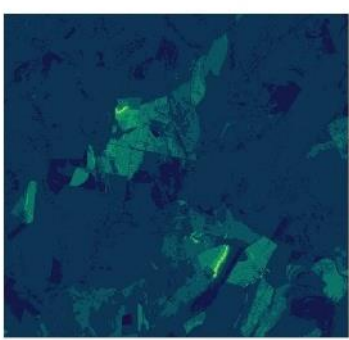

Níveis de alteração

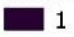

1

2

要

4

$\square 6$

7

8

9

$\square 10$

SRC: SIRGAS $2000 /$ UTM zona $22 \mathrm{~s}$

Fonte: Agência Espacial Européia (ESA), 2017. Elaboração: os autores, 2019.

A validação por meio do Coeficiente Kappa resultou em uma concordância de 55,2\%. A amostragem randômica seleciona polígonos aleatórios independentemente de sua área, contudo, um aspecto importante é o fato de haver uma concentração de polígonos de maior área localizado na porção sul da microrregião (Figura 5), sinalizando que esta porção do território indica grandes alterações provocadas pelos incêndios florestais. (Figura 5). 
Figura 5 - (A) Distribuição das amostras para avaliação do desempenho $\Delta$ NBR. (B) Distribuição das amostras analisadas para a atribuição do índice kappa.

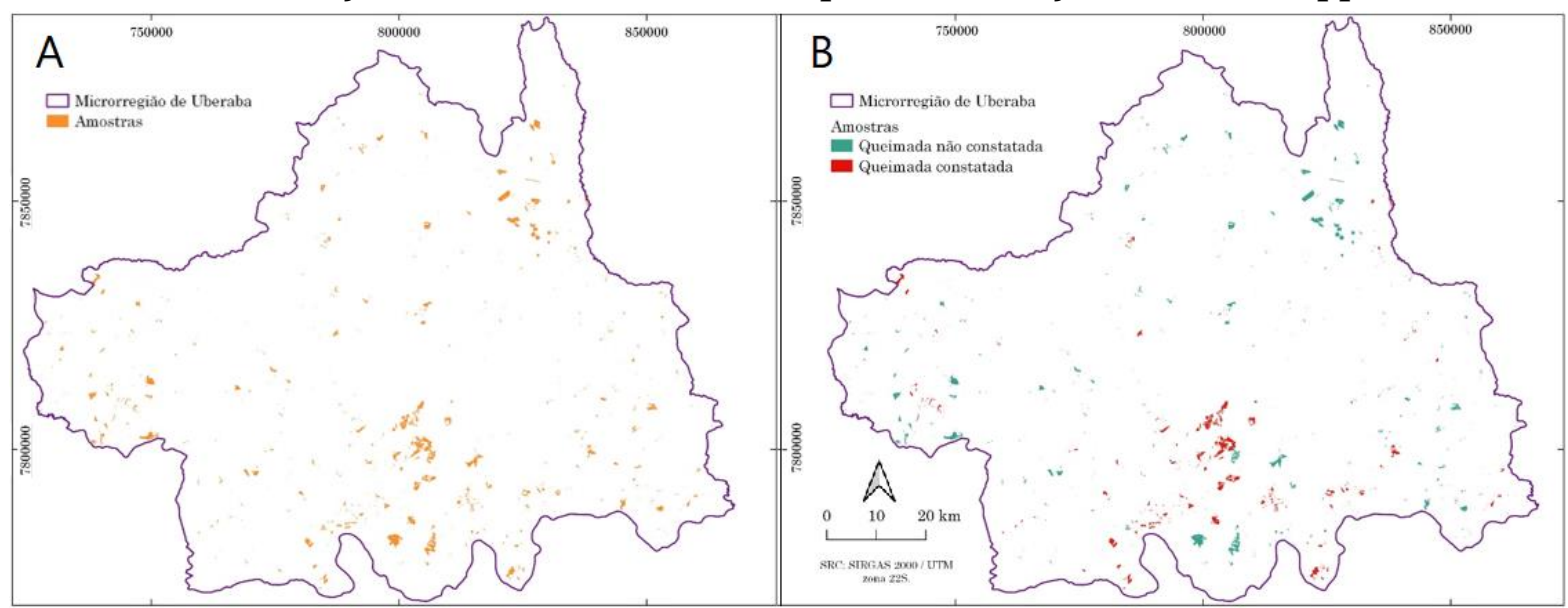

Fonte: Agência Espacial Européia (ESA), 2017. Elaboração: os autores, 2019.

Os principais tipos de uso do solo afetados pelo incêndio são agrícolas, com destaque para o cultivo semi-perene e o cultivo perene (Tabela 2), ambos possuem uma grande área e uma maior intensidade das queimadas. A classe semi-perene está associadas à cultura da cana de açúcar. A floresta plantada, característica na região, é da espécie eucalipitus e a formação campestre detectadas nas queimadas tem relação com áreas de pastagens com árvores dispersas ou campo sujo.

Tabela 2 - Áreas atingidas e usos de solo

\begin{tabular}{|c|c|c|c|}
\hline Nivel & Uso do Solo & Área em Ha. & Área total em Ha. \\
\hline 5 & Cultivo Anual e Perene & 1328,610 & \multirow{2}{*}{1617,134} \\
\hline 6 & Cultivo Anual e Perene & 288,524 & \\
\hline 5 & Cultivo Semi-Perene & 6628,170 & \multirow{5}{*}{8820,244} \\
\hline 6 & Cultivo Semi-Perene & 2118,340 & \\
\hline 7 & Cultivo Semi-Perene & 64,336 & \\
\hline 8 & Cultivo Semi-Perene & 1,144 & \\
\hline 9 & Cultivo Semi-Perene & 8,254 & \\
\hline 5 & Floresta Plantada & 5,411 & \multirow{2}{*}{92,606} \\
\hline 6 & Floresta Plantada & 87,196 & \\
\hline 5 & Formação Campestre & 65,310 & \multirow{2}{*}{66,394} \\
\hline 7 & Formação Campestre & 1,084 & \\
\hline 5 & Formação Florestal & 111,041 & \multirow{3}{*}{114,222} \\
\hline 6 & Formação Florestal & 2,664 & \\
\hline 9 & Formação Florestal & 0,518 & \\
\hline 5 & Formação savanica & 85,168 & \multirow{2}{*}{92,657} \\
\hline 6 & Formação savanica & 7,490 & \\
\hline 5 & Pastagem & 286,443 & \multirow{3}{*}{304,576} \\
\hline 6 & Pastagem & 17,413 & \\
\hline 7 & Pastagem & 0,720 & \\
\hline 5 & Rios e Lagos* & 20,350 & \multirow{2}{*}{21,449} \\
\hline 6 & Rios e Lagos* & 1,098 & \\
\hline & Total & & 11129,283 \\
\hline
\end{tabular}

* "Rio e Lagos" são erros de medidas de posicionamento decorrentes das diferenças de resolução espacial dos pixels do S2-MSI (20 metros) em do raster gerado pelo MapBiomas (30 metros). Elaborado pelos autores, 2019. 


\section{DISCUSSÃO}

A avaliação dos impactos dos incêndios florestais em ecossistemas de regiões temperadas e florestas boreais tem sido feita aplicando-se o $\triangle \mathrm{NBR}$, mas alguns estudos argumentam que a efetividade da estimativa da severidade da queima é melhor para alguns tipos de culturas ou coberturas do que para outros, além de que, a mensuração da severidade das queimadas pelo $\triangle$ NBR requer a definição das classes por meio de levantamentos de campo, de modo a ajustar o índice à realidade da região estudada (BOUCHER et al. 2016; ALLEN; SORBEL, 2008). Este estudo avaliou a severidade dos incêndios por interpretação visual de imagem de satélite, uma vez que os episódios analisados ocorreram um ano antes da realização desta pesquisa, e as inspeções de campo realizadas detectaram que as vegetações afetadas já se encontravam em processo de regeneração, impossibilitando a composição de um índice de queimada que, segundo Key; Benson (2006), se faz com base no julgamento ocular e a identificação de uma gama de variação dentro da área queimada. Desta forma, é importante fazer os levantamentos de campo logo após a ocorrência dos incêndios.

A aplicação do $\triangle$ NBR tem melhores resultados quando utilizado para estimar a severidade da queima em áreas com episódios de incêndios conhecidos. Para fins de detecção de áreas queimadas desconhecidas, o risco de incidir em uma intepretação equivocada é alto. Por exemplo, se entre a data do NBR pré-fogo e a data do NBR pós-fogo, uma área agrícola foi colhida ou teve sua vegetação suprimida não por fogo, o solo exposto poderá ser confundido com uma área queimada, daí o fato de o coeficiente kappa aplicado nesta pesquisa apresentar valores moderados.

Aqui, o propósito é uma análise temporal de dois meses, a escolha deste recorte se deve aos significativos danos decorrentes dos incêndios na região (CRUVINEL, 2021). Contudo, as análises também podem se dar sobre escalas temporais maiores, com verificação de distintos limiares de classificação e resoluções temporais, permitindo a construção de uma variedade ampla de cenários (BRAGA, 2016). Os erros de classificação são comuns na aplicação $\triangle \mathrm{NBR}$, e tais confusões ocorrem devido a mistura do índice com outras refletâncias. Em estudo realizado no Mato Grosso, Rosan; Alcântara (2015) aplicaram o método proposto por Gao (1996), cujo propósito foi reduzir as áreas com quantidades significativas de umidade, pois se confundiam com áreas queimadas. Os autores atestaram haver obtido bons resultados na minimização de confusões, uma vez que detectaram que áreas com alto teor de umidade apresentaram confusão espectral com áreas queimadas. O teste piloto com uso do NDWI a fim de minimizar as confusões não surtiu bons resultados neste estudo, pois eliminou do modelo algumas áreas queimadas indesejadas. Diante disso, optou-se pela interpretação visual, como procedimento para a redução de confusões de classificação.

\section{CONCLUSÕES}

Este estudo mostra que as áreas mais afetadas pelos incêndios florestais na Microrregião de Uberaba são utilizadas para culturas perenes e semi-perenes, sendo intensos na cultura da cana de açúcar, como fora detectado neste estudo por meio de interpretação visual de imagens de satélite. A utilização do NBR e sua variante temporal $\triangle$ NBR é um meio essencial para analisar a severidade das queimadas e construir uma escala de alteração. Por meio deste instrumento de análise é possível mensurar as alterações na paisagem provocadas pelos incêndios e relacioná-las aos tipos de cobertura e usos do solo.

No período da estiagem os incêndios florestais na Microrregiao de Uberaba tem sido recorrentes e tais eventos tem se configurado como desastres, uma vez que a intensidade de alguns impossibilitam o combate pela defesa civil, resultando em grandes áreas in incendiadas e atingindo não só cultivos, como também formações naturais ainda preservadas, tais como matas ciliares. O manejo do solo com uso do fogo é uma prática regulamentada em Minas Gerais pela Resolução Conjunta SEMAD/IEF nº 2.988, de 24 de julho de 2020 (ESTADO DE

Cláudio M. Pantaleão Júnior, Ricardo V. Ferreira. Avaliação do desempenho do índice $\Delta$ NBR para a identificação de áreas incendiadas (...) Brazilian Geographical Journal: Geosciences and Humanities research medium, 
MINAS GERAIS, 2020). Contudo, só é admitido para fins agropastoril, florestal ou fitossanitário, além de fins de pesquisa científica e tecnológica, desde que autorizado por órgão competente, a depender dos fins relacionados. Dentre os órgão emissores de licenças estão o Instituto estadual de Florestas (IEF) e Secretaria de Estado de Meio Ambiente e Desenvolvimento Sustentável - Semad. A não autorização implica em crime previsto na Lei 9.605/1998, no Art.41 (BRASIL, 1998), também sendo vigente na Lei 12.651/2012 (BRASIL, 2012), Art. 38-40.

Para reduzir essas ações, é necessário que haja uma forma eficaz de monitoramento, nesse sentido, as técnicas de sensoriamento remoto se fazem operacionais para o apoio à defesa civil, contribuindo para a análise das alterações na paisagem decorrentes dos incêndios florestais.

Considerando a relação dos incêndios com atividades da produção agrícola, uma hipótese para estudos futuros seria analisar a relação do manejo do solo com as atividades agrossilvipastoris, já que as áreas mais alteradas correspondem aos cultivos sazonais ou anuais.

\section{REFERÊNCIAS}

AB'SÁBER. A. N. Os domínios da natureza no Brasil: potencialidades paisagísticas. Ateliê Editorial, São Paulo, 2003. 159p.

ALLEN, J.L.; SORBEL, B. Assessing the differenced Normalized Burn Ratio's ability to map burn severity in the boreal forest and tundra ecosystems of Alaska's national parks. International Journal of Wildland Fire 17, 2008. pp. 463-475. doi: https://doi.org/10.1071/WFo8034

BOUCHER, J.; BEAUDOIN A.; HÉBERT C.; GUINDON L.; BAUCE É. Assessing the potential of the differenced Normalized Burn Ratio (dNBR) for estimating burn severity in eastern Canadian boreal forests. International Journal of Wildland Fire 26, 2016. pp. 32-45. https://doi.org/10.1071/WF15122

BRAGA, J.V. Mapeamento de área queimadas usando séries temporais normalizadas derivadas de dados NBR-MODIS durante o período de 2001-2014 no parque nacional das Emas. Dissertação de Mestrado em Geografia. Universidade de Brasília. Brasília, 2016. 66p. Doi: http://dx.doi.org/10.26512/2015.12.D.20358

BRASIL. Presidência da República, Casa Civil, Subchefia para Assuntos Jurídicos. Lei No 9.605, de 12 de Fevereiro de 1998. Dispõe sobre as sanções penais e administrativas derivadas de condutas e atividades lesivas ao meio ambiente, e dá outras providências. Brasília, DF, 12 de fevereiro de 1998.1 Disponível em: <http://www.planalto.gov.br/ccivil_03/leis/l9605.htm>. Acesso em 19 nov 2019, Diário Oficial da União em: 13 de fevereiro de 1998.

BRASIL. Presidência da República, Casa Civil, Subchefia para Assuntos Jurídicos. Lei No 12.651, de 25 de Maio de 2012. Dispõe sobre a proteção da vegetação nativa; altera as Leis $\mathrm{n}^{0} \mathrm{~S}$ 6.938, de 31 de agosto de 1981, 9.393, de 19 de dezembro de 1996, e 11.428, de 22 de dezembro de 2006; revoga as Leis ${ }^{\circ} \mathrm{S} 4.771$, de 15 de setembro de 1965, e 7.754, de 14 de abril de 1989, e a Medida Provisória ${ }^{0}$ 2.166-67, de 24 de agosto de 2001; e dá outras providências. Brasília, DF, 25 de maio de 2012. Disponível em: < http://www.planalto.gov.br/ccivil_03/_Ato20112014/2012/Lei/L12651.htm > Acessado em 13 dezembro de 2019, Diário Oficial da União em: 25 maio de 2012.

BRITO, J L S; REIS, L N G. Mapeamento das áreas de conversão do uso da terra para cana-deaçúcar na mesorregião do Triângulo Mineiro/Alto Paranaíba-MG por meio de imagens TM/LANDSAT. Caminhos de Geografia, Uberlândia v. 13, n. 41 mar/2012 pp. 170-186. Disponível

em: 
$<$ http://www.seer.ufu.br/index.php/caminhosdegeografia/article/view/16522>. Acesso em 15 dez 2020

CARDOZO, F. S.; MARTINS, F. S. R.; PEREIRA, L. O.; SATO, L. Y.; MOURA, Y. M.; PEREIRA, G.; SHIMABUKURO, Y. E. Avaliação de áreas queimadas a partir dos índices espectrais NDVI e NDBR. Anais do XV Simpósio Brasileiro de Sensoriamento Remoto (SBSR), Curitiba, 2011. pp. 7050-7057. Disponível em: < http://marte.sid.inpe.br/col/dpi.inpe.br/marte/2011/07.27.21.58/doc/p1429.pdf?languageb utton=pt-BR $>$. Acesso em 15 dez 2019.

CHUVIECO E.; AGUADO I.; JURDAO S.; PETTINARI M. L.; YEBRA M.; SALAS J.; HANTSON S.; DE LA RIVA J.; IBARRA P.; RODRIGUES M.; ECHEVERRÍA M.; AZQUETA D.; ROMÁN M. V.; BASTARRIKA A.; MARTÍNEZ S.; RECONDO C.; ZAPICO E.; MARTÍNEZ-VEGA F. J. Integrating geospatial information into fire risk assessment. International Journal of Wildland Fire 23, 2014. pp. 606-619. http://dx.doi.org/10.1071/WF12052

CHUVIECO, E.; MARTÍN, M.; MARTÍNEZ-FERNANDEZ, J.; SALAS, J. Geografía e incêndios forestales. Serie Geográfica. v. 7, 1998. pp. 11-17.

COHEN, J. A coefficient of agreement for nominal scales. Educational and Psychological Measurement, 20, 1960. pp. 37-46. Doi: https://doi.org/10.1177\%2F001316446002000104

CONGALTON, R. G. A review of assessing the accuracy of classifications of remotely sensed data. Remote Sensing of Environment. v. 37, 1991. pp. 35-46. Doi: https://doi.org/10.1016/0034-4257(91)90048-B

CRUVINEL, L. H. $8^{\circ}$ BBMMG divulga comparativo de incêndios em vegetação nos últimos quatro anos em Uberaba. Jornal da Manhã, Uberaba, 7 jan 2021. Disponível em <https://jmonline.com.br/novo/?noticias,5,POL\%C3\%8DCIA,207008>. Acesso em 13 jan 2021.

DUBREUIL, V.; FANTE, K. P.; PLANCHON, O.; SANT'ANNA NETO, J. L. Os tipos de climas anuais no Brasil : uma aplicação da classificação de Köppen de 1961 a 2015. Confins [online], v. 37, 2018. Disponível em: <http://journals.openedition.org/confins/15738>, acessado em dezembro de 2019. Doi: https://doi.org/10.4000/confins.15738

ESTADO DE MINAS GERAIS. Resolução conjunta SEMAD/IEF No 2.988, de 24 de julho de 2020. Diário do Executivo, Minas Gerais, 25/07/2020. Secretaria de Estado do Meio Ambiente e do Desenvolvimento Sustentável. Caderno 1, Belo Horizonte, MG, pág. 08, 25 jul, 2020. Disponível em: < http://jornal.iof.mg.gov.br/xmlui/handle/123456789/23685.3>. Acesso em 15 dez 2020.

GAO, B.C. NDWI - A normalized difference water index for remote sensing of vegetation liquid water from space. Remote Sensing of Environment. v.58, 1996. pp. 257-266. Doi: https://doi.org/10.1016/So034-4257(96)00067-3

GOMES DE SOUZA, A.; CLEPS JUNIOR, J. Expansão da cana-de-açúcar no Triângulo Mineiro e os efeitos sobre a agricultura familiar e o trabalho rural. Revista Tópos, V. $3, \mathrm{~N}^{\circ} 2$, Presidente Prudente, 2009. pp. 8 - 35. Disponível em: < https://revista.fct.unesp.br/index.php/topos/article/view/2235/o > . Acesso em $21 \mathrm{dez} 2020$.

IBGE. Divisão regional do Brasil em Mesorregiões e Microrregiões. V.1. Rio de Janeiro. 1990. 137p.

IBGE. . 2019 Disponível em: <https://www.ibge.gov.br/geociencias/organizacao-doterritorio/malhas-territoriais/15774-malhas.html?=\&t=downloads $>$ Acesso em 09 jan 2020.

IBGE. Mapa de biomas do Brasil. Brasil, 2004.

INPE. Banco de Dados de queimadas. Disponível em: http://www.inpe.br/queimadas/bdqueimadas. Acesso em: 11 de jan 2021. 
KEY, C. H.; BENSON, N. Landscape assessment (LA) sampling and analysis methods. USDA Forest Service, Rocky Mountain Research Station, General Technical Report RMRS-GTR-164-CD. (Fort Collins, CO), 2006. Disponível em: https://www.fs.fed.us/rm/pubs/rmrs gtr164/rmrs gtr164 13 land assess.pdf. Acesso em 12 jan 2021.

KOLDEN C.A.; SMITH A.M.; ABATZOGLOU J.T. Limitations and utilisation of Monitoring Trends in Burn Severity products for assessing wildfire severity in the USA. International Journal of Wildland Fire 24, 2015. pp. 1023-1028. doi: https://doi.org/10.1071/WF15082

KOUTSIAS, N.; KARTERIS, M. Logistic regression modeling of multi temporal Thematic Mapper data for burned are mapping. International Journal of Remote Sensing, v. 19, p. 3499-3514, 1998. pp. 3499-3514. Doi: https://doi.org/10.1080/014311698213777

MAPBIOMAS. Cobertura e uso de solo. Disponível em: <http://plataforma.mapbiomas.org/map\#coverage> Acessado em 18 novembro 2019.

MEDEIROS, M. B.; FIEDLER, N. C. Incêndios florestais no Parque Nacional Da Serra Da Canastra: desafios para a conservação da biodiversidade. Ciência Florestal, Santa Maria, v. 14, n. 2, p. 157-168. Doi: https://doi.org/10.5902/198050981815

NOVAIS, G. T.; BRITO, J. L. S.; SANCHES, F. O. Unidades climáticas do Triângulo Mineiro/Alto Paranaíba. Revista Brasileira de Climatologia. Ano 14, vol. 23, jul/dez. 2018. Doi: http://dx.doi.org/10.5380/abclima.v23io.58520

PEREIRA, A. A. Mapeamento automático de queimadas no bioma Cerrado utilizando sensores orbitais. Tese de doutoramento, Universidade Federal de Lavras, Programa de Pós-Graduação em Engenharia Florestal, Lavras, 2017. 215p. Disponível em < http://repositorio.ufla.br/jspui/handle/1/15258> Acesso em 15 dez 2019.

PROJETO MAPBIOMAS. Coleção 2017 da Série Anual de Mapas de Cobertura e Uso de Solo do Brasil, 2019. Acessado em 15/12/2019 através do link: https://plataforma.mapbiomas.org/

ROSAN, T. M.; ALCÂNTARA, E. Detecção de áreas queimadas e severidade a partir do índice espectral $\triangle$ NBR. Anais do XVII Simpósio Brasileiro de Sensoriamento Remoto (SBSR), 17, 2015, João Pessoa. pp. 526-533. Disponível em: < http://www.dsr.inpe.br/sbsr2015/files/p0104.pdf>. Acesso em 20 dez 2019.

SANTOS, J. F.; SOARES, R. V.; BATISTA, A. C. Perfil dos incêndios florestais no Brasil em áreas protegidas no período de 1998 a 2002. FLORESTA, Curitiba, PR, v. 36, n. 1, jan./abr. 2006. Doi: http://dx.doi.org/10.5380/rf.v36i1.5510

SANTOS, P. R.; PEREIRA G.; CARDOZO, F. S.; RAMOS, R. C.; FERREIRA, A. B. R.; RESENDE, F. C. Análise das queimadas no cerrado e sua relação com o NDVI para os anos de 2000 - 2014. Revista de Geografia V.35, No. 2, Recife, 2018. pp. 134-157. Disponível em: < https://periodicos.ufpe.br/revistas/revistageografia/article/view/229312/29075>. Acesso em: 15 dez 2019.

SILVA, F.; PESTANA, A.; MARTINS, L. Sensoriamento remoto para detecção de queimadas no cerrado maranhense: uma aplicação no Parque Estadual do Mirador. Revista Geográfica Acadêmica. v.13, n.2, 2019. pp. 90-105. Disponível em: <https://revista.ufrr.br/rga/article/view/5759/2747> Acesso em: 12 jan 2021.

Recebido em: 08/01/2020.

Aprovado para publicação em: 28/12/2020.

Cláudio M. Pantaleão Júnior, Ricardo V. Ferreira. Avaliação do desempenho do índice $\Delta$ NBR para a identificação de áreas incendiadas (...) Brazilian Geographical Journal: Geosciences and Humanities research medium, 